\title{
Toxicological effects of As (V) in juvenile rockfish Sebastes schlegelii by a combined metabolomic and proteomic approach ${ }^{\text {h }}$
}

\author{
Lanlan $\mathrm{Xu}^{\mathrm{a}, \mathrm{c}}$, Zhen $\mathrm{Lu}^{\mathrm{a}, \mathrm{c}}$, Chenglong Ji ${ }^{\mathrm{a}, \mathrm{b}}$, Ming Cong ${ }^{\mathrm{a}}$, Fei Li ${ }^{\mathrm{a}}$, Xiujuan Shan ${ }^{\mathrm{b}}$, \\ Huifeng $\mathrm{Wu}^{\mathrm{a}, \mathrm{b}, *}$ \\ ${ }^{a}$ CAS Key Laboratory of Coastal Environmental Processes and Ecological Remediation, Yantai Institute of Coastal Zone Research (YIC), Chinese Academy of \\ Sciences (CAS), Shandong Key Laboratory of Coastal Environmental Processes, YICCAS, Yantai, 264003, PR China \\ ${ }^{\mathrm{b}}$ Laboratory for Marine Fisheries Science and Food Production Processes, Qingdao National Laboratory for Marine Science and Technology, Qingdao, \\ 266237, PR China \\ ${ }^{\mathrm{C}}$ University of Chinese Academy of Sciences, Beijing, 100049, PR China
}

\section{A R T I C L E I N F O}

\section{Article history:}

Received 1 July 2019

Received in revised form 2 September 2019

Accepted 30 September 2019

Available online 4 October 2019

\section{Keywords:}

Arsenic

Toxicological effect

Juvenile rockfish

Proteomics

Metabolomics

\begin{abstract}
A B S T R A C T
Arsenic (As) is a metalloid element that is ubiquitous in the marine environment and its contamination has received worldwide attention due to its potential toxicity. Arsenic can induce multiple adverse effects, such as lipid metabolism disorder, immune system dysfunction, oxidative stress and carcinogenesis, in animals. Inorganic arsenic includes two chemical forms, arsenite (As (III)) and arsenate (As (V)), in natural environment. As $(\mathrm{V})$ is the dominant form in natural waters. In the present study, metabolomic and proteomic alterations were investigated in juvenile rockfish Sebastes schlegelii exposed to environmentally relevant concentrations of As $(\mathrm{V})$ for $14 \mathrm{~d}$. The analysis of iTRAQ-based proteomics combined with untargeted NMR-based metabolomics indicated apparent toxicological effects induced by As (V) in juvenile rockfish. In details, the metabolites, including lactate, alanine, ATP, inosine and phosphocholine were significantly altered in As-treated groups. Proteomic responses suggested that As (V) could not only affected energy and primary metabolisms and signal transduction, but also influenced cytoskeleton structure in juvenile rockfish. This work suggested that the combined proteomic and metabolomic approach could shed light on the toxicological effects of pollutants in rockfish S. schlegelii.
\end{abstract}

() 2019 Elsevier Ltd. All rights reserved.

\section{Introduction}

Marine metal contamination caused by anthropogenic activities in the Bohai Sea has received great concerns from researchers ( $\mathrm{Li}$ et al., 2018). Arsenic (As) is a metalloid element with metallic and non-metallic properties and usually classified as a metal element (Tišler and Zagorc-Končan, 2002). Due to its non-necessity and widespread existence, As has become a typical coastal and marine contaminant in the Bohai Sea (Zhuang and Gao, 2015). Gao et al. (2014) reported that the As concentrations in seawater changed frequently and seasonally and the maximum concentration had been up to $3.4 \mu \mathrm{g} / \mathrm{L}$ in coastal and estuary areas along the Bohai Sea.

\footnotetext{
This paper has been recommended for acceptance by Dr. Sarah Harmon.

* Corresponding author. CAS Key Laboratory of Coastal Environmental Processes and Ecological Remediation, Yantai Institute of Coastal Zone Research (YIC), Chinese Academy of Sciences (CAS), Shandong Key Laboratory of Coastal Environmental Processes, YICCAS, Yantai, 264003, PR China.

E-mail address: hfwu@yic.ac.cn (H. Wu).
}

The toxicity of As to organisms depends on its species. Generally, the inorganic forms of As are the most toxic forms in marine ecosystems (Erickson et al., 2019). Among the inorganic forms, arsenate (As (V)) is the dominant form in natural waters.

The potential toxicity of As has received worldwide attention due to its frequent detection in the environment. As can stimulate numerous molecular events in connection with lipid metabolism disorder, immune system dysfunction, oxidative stress and carcinogenesis in organisms, which have been well documented in a variety of organisms (Chen et al., 2018a,b; Chen et al., 2019; Ramsey et al., 2013; Szymkowicz et al., 2019; Xu et al., 2013; Yu et al., 2016). Since researchers often take advantage of traditional toxicological approaches to focus on a known class of toxicity-responsive molecules to draw out the toxic mechanisms, it is reluctant to discover new biological molecules associated with toxicological effects and presents initial and less comprehensive evaluations on toxicological reactions of pollutants in organisms (Ji et al., 2014).

Recently, omics approaches in system biology, such as transcriptomics, proteomics and metabolomics, have been proposed to 
supervise the terrestrial or marine ecosystems and these methods have been used to elucidate the potential toxicity caused by toxic substances to organisms (Chen et al., 2018a,b; García-Sevillano et al., 2013; Ji et al., 2019; Williams et al., 2011). Metabolomics focuses exactly on the alterations of low molecular metabolites $(<1000 \mathrm{Da})$ within cells, tissues or biofluids in organisms (Song et al., 2018; Viant et al., 2003) and offers fresh insights into the toxicological effects of environmental stressors (Jones et al., 2008). Among modern analytical techniques, the proton nuclear magnetic resonance $\left({ }^{1} \mathrm{H}-\mathrm{NMR}\right)$ spectroscopy is powerful for the detection of endogenous low-molecular weight metabolites in biological samples, since all metabolites contain protons. Moreover, NMR is a rapid and nondestructive analytical technique that can provides rich structural and quantitative information of metabolites. Due to these advantages, NMR-based metabolomics has been extensively applied in ecotoxicology (Brandão et al., 2015; Cappello et al., 2016a, b). Proteomics may provide the significant discrepancies between contaminant-stressed and control conditions, which offer us a direct interpretation of toxicity mechanism after pollution exposure to organisms (Nicholson and Lindon, 2008; Salazar-Coria et al., 2019). The combination of metabolomics and proteomics can provide system-level snapshots of the metabolism of a cell or organism under the stress of toxicants (Chen et al., 2017).

Fishes are considered to be significant biomonitors in aquatic systems for the metal pollution assessment (Rashed, 2001). Rockfish Sebastes schlegelii is one of the most important economic species owing to its high demand, rapid growth and appreciated flesh. It is not only distributed in the Korean peninsula and Japan, but also distributed around the Bohai Sea, the Yellow Sea, and the East China Sea (Chen et al., 1994; Nakagawa et al., 2007). Rockfish has been widely used as experimental animal in marine ecotoxicology (Lee et al., 2018; Kim and Kang, 2017; Kim and Kang, 2015). Previous studies have illustrated that As could induce hyperglycemic effect, block energy production and normal cell signaling as well as increase the metallothionein-I and metallothionein-II mRNA levels in fish (Garg et al., 2008; Kreppel et al., 1993). However, the underlying toxic mechanisms explaining its responses to metal contaminants have been largely unexplored. The aim of this work was to unravel the toxicological responses in juvenile rockfish to environmentally relevant concentrations of As and better understand the arsenate-induced effects in rockfish S. schlegelii using a combined proteomic and metabolomic approach.

\section{Materials and methods}

\subsection{Experimental animals and conditions}

In this work, the juvenile rockfish was selected for As exposures. Seventy-two individuals of juvenile rockfish S. schlegelii (body length: $6.5-7.0 \mathrm{~cm}$ ) were purchased from a local culturing farm in Yantai, China. After transported to the laboratory, the fish were allowed to acclimate in aerated seawater $\left(20^{\circ} \mathrm{C}, 33 \mathrm{ps} \mu\right)$ for 1 week. After acclimatization, the fish were randomly divided into three groups (control, 5 and $50 \mu \mathrm{g} / \mathrm{L} \mathrm{As}(\mathrm{V})$ in $\mathrm{Na}_{2} \mathrm{HAsO}_{4}$ ) each containing two replicate tanks with 12 individuals. The seawater As concentration from some areas in the Bohai Sea reached $12.4 \mu \mathrm{g} / \mathrm{L}$ (Gao et al., 2014; Zhang, 2001). In this work, the orders of magnitude of As concentrations for exposure were environmentally relevant. During the acclimatization and exposure periods, the fish were kept under a photoperiod of $12 \mathrm{~h}$ light and $12 \mathrm{~h}$ dark, and fed with the commercial bait daily. After exposure for 14 days, fish from each tank were immediately sampled for further analyses. The whole fish samples were quickly snap-frozen in liquid nitrogen and ground into powder. Then the powder of each sample was divided into three tubes and then stored at $-80^{\circ} \mathrm{C}$.

\subsection{NMR spectroscopy-based metabolomic analysis}

Metabolite extraction of juvenile rockfish was performed using the modified extraction protocol as described previously (Ji et al., 2015). All the tissues (ca. $100 \mathrm{mg}$ wet weight) were homogenized and extracted in $4 \mathrm{~mL} / \mathrm{g}$ of methanol, $5.25 \mathrm{~mL} / \mathrm{g}$ of water and $2 \mathrm{~mL} / \mathrm{g}$ of chloroform (Lin et al., 2007; Wu et al., 2008). Only metabolite extracts in methanol/water were analyzed on a Bruker AV 500 NMR spectrometer performed at $500.18 \mathrm{MHz}$ (at $25^{\circ} \mathrm{C}$ ) as described previously (Ji et al., 2015).

The ProMetab software in Matlab (version 7.0; The MathWorks, Natick, MA, USA) was used to process NMR spectra (Liu et al., 2011). Each spectrum was segmented into $0.005 \mathrm{ppm}$ bins from 0.2 to $10.0 \mathrm{ppm}$. Then, these NMR spectra were generalized log transformed with a transformation parameter equivalent to $2.0 \times 10^{-9}$ to stabilize the variance across the spectral bins (Liu et al., 2011). The obtained NMR spectral matrix data were mean-centered prior to multivariate data analysis. More details about metabolomic analysis were described in the Supporting Information.

\section{3. iTRAQ-based quantitative proteomic analysis}

Protein extraction was performed according to the methodology described in a previous study with some modifications (Isaacson et al., 2006). Briefly, samples ( $0.1 \mathrm{~g}$ ) from 3 individuals of juvenile rockfish were pooled as one replicate, and proteins were extracted using cold phenol extraction buffer. The concentrations of protein extracts were determined by BCA method (Smith et al., 1985). iTRAQ technique was employed to quantitative proteomic analysis. The iTRAQ labeling of peptides from fish samples were performed using iTRAQ 8-plex reagents (Applied Biosystems, Foster City, CA, USA) according to the manufacturer's protocol. Eight samples (two biological replicates for control group and three replicates for each As-treated group) were labeled with the iTRAQ tags. Data was processed with Protein Pilot Software (version 5.0, AB SCIEX, USA) against Perciformes database using the Paragon algorithm. The experimental data from tandem mass spectrometry (MS) was used to match the theory data to identify the proteins. The protein ratios in each replicate were then quantified based on the summed intensities of the matched spectrum. These ratios from the biological replicates were evaluated by Student's $t$-test combined with the Benjamini-Hochberg correction (Han et al., 2013). To calculate the relative protein levels, proteins with corrected $p$ values less than 0.05 and average iTRAQ ratios of $\geq 1.3$ or $\leq 0.77$ were considered to be significantly differential. The Gene ontology (GO) databases (http://www.geneontology.org) and the Kyoto Encyclopedia of Genes and Genomes (KEGG) database (http:// www.genome.jp/kegg/) were used to classify and group these identified proteins. Further details regarding proteomic analysis were described in the Supporting Information S1.

\subsection{Determination of As in juvenile rockfish samples}

Nine powered samples of juvenile rockfish in each group were dried at $80^{\circ} \mathrm{C}$ to constant weights and then digested in concentrated nitric acid $\left(\mathrm{HNO}_{3}, 70 \%\right.$, Fisher Scientific) using a microwave digestion system (CEM, MAR5). These fish samples in concentrated $\mathrm{HNO}_{3}$ were heated in the microwave oven at $200{ }^{\circ} \mathrm{C}$ for $15 \mathrm{~min}$ and clear solutions were obtained. The digested samples were transferred to $10 \mathrm{~mL}$ polypropylene tubes and filled up to $10 \mathrm{~mL}$ with ultrapure water (MilliQ plus) before arsenic concentration determination by ICP-MS technique (Agilent 7500i, Agilent Technologies Co. Ltd, Santa Clara, CA, USA). The As concentrations in juvenile rockfish were expressed as means \pm standard deviation. One way analysis of variance (ANOVA) was conducted on the As 
concentrations from control and As treatments, respectively, using SPSS statistics. The $p$ values less than 0.05 were considered statistically significant.

\section{Results}

\subsection{Arsenic accumulation}

Fish can effectively bioaccumulate metal contaminants from the aquatic environments (Kumari et al., 2017). The concentrations of total arsenic in juvenile rockfish from control and both As treatments were determined using ICP-MS technique. As shown in Fig. 1, the juvenile rockfish from both As treatments exhibited significant $(p<0.05)$ As accumulations in the whole tissues. In details, the concentrations of total As were $1.37 \pm 0.17$ and $1.41 \pm 0.07 \mu \mathrm{g} / \mathrm{g}$ dry weight in the juvenile rockfish exposed to 5 and $50 \mu \mathrm{g} / \mathrm{L}$ waterborne As for $14 \mathrm{~d}$, respectively. However, the As concentrations in both low and high As-treated groups were only $17.1 \%$ and $20.5 \%$ higher than the As concentration in the control group. In addition, the accumulations in both As treatments were not significantly $(p>0.05)$ different.

\subsection{Metabolic responses in juvenile rockfish to As exposures}

Thirty-four metabolites were identified in juvenile rockfish samples (Fig. 2). Several classes of metabolites were identified including amino acids (branched chain amino acids (BCAAs), arginine, threonine, alanine, glutamate, tyrosine, histidine, phenylalanine, glycine, etc.), organic acids (lactate and acetate), energy metabolites (phosphocholine, creatine phosphate, glucose and ATP), intermediates in the Krebs cycle (fumarate and succinate), and osmolytes (taurine, dimethylamine and trimethylamine $N$ oxide). Principal component analysis (PCA) was performed on the NMR spectral data from control and As-treated groups and significant separations were observed along PC1 and PC2 axes (Fig. 3), respectively. In addition, the two As exposed-groups were separated along PC2 axis, indicating the significant metabolic differences between these two As treatments. Then, O-PLS-DA was performed on the NMR spectral data from control and each Astreated group. As shown in Fig. 4A and B, the O-PLS models generated from control and As treatments indicated their robustness and reliability with $Q^{2}$ values of 0.886 and 0.651 , respectively.

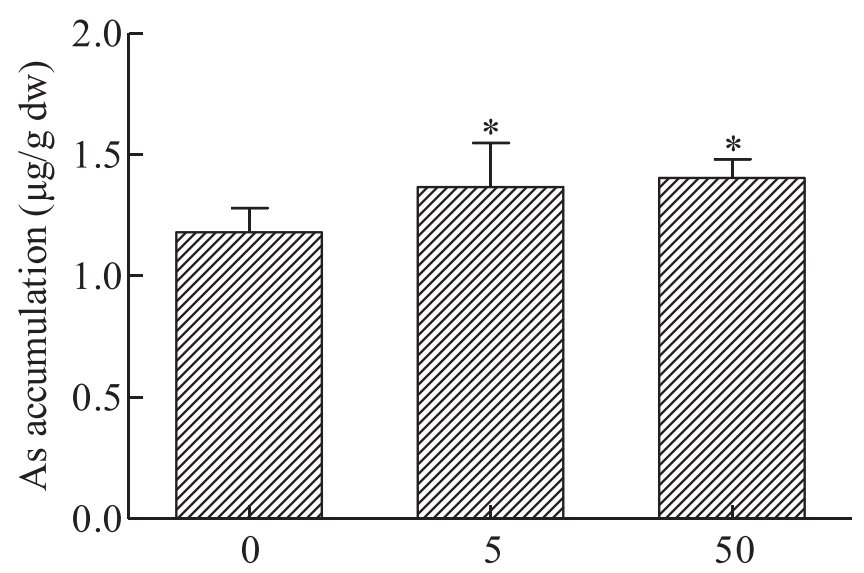

As concentration for exposure $(\mu \mathrm{g} / \mathrm{L})$

Fig. 1. The average concentrations of As in juvenile rockfish $S$. schlegeli after 14 days exposure of 5 and $50 \mu \mathrm{g} / \mathrm{L}$ As. As concentrations are presented as the mean \pm standard deviation. Statistical significances $\left(p<0.05,{ }^{*}\right)$ between control and As treatments were determined by one way ANOVA.

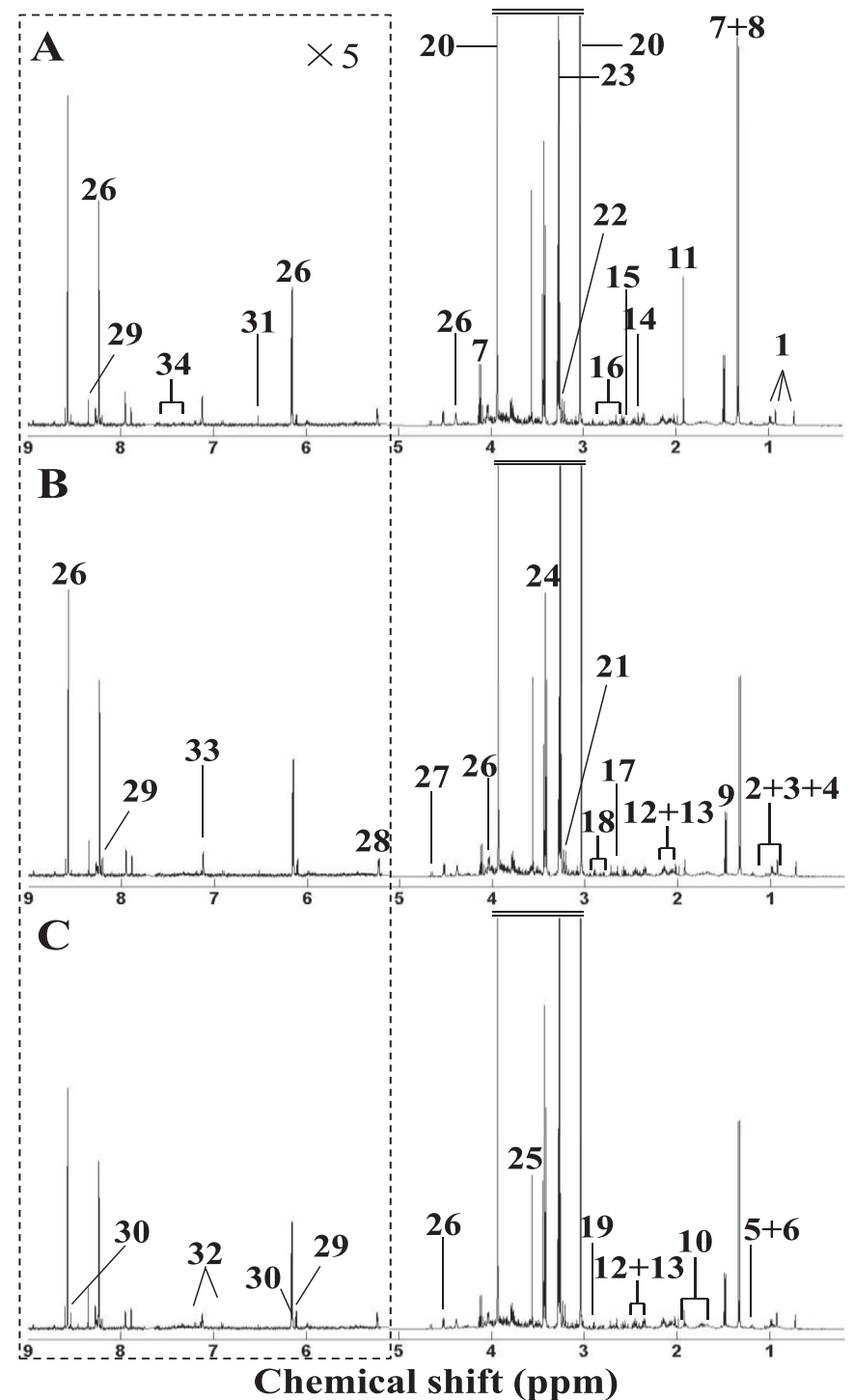

Fig. 2. Typical ${ }^{1} \mathrm{H}$ NMR spectra of tissue extracts of juvenile rockfish $S$. schlegeli from the control (A), $5 \mu \mathrm{g} / \mathrm{L}$ As (B) and $50 \mu \mathrm{g} / \mathrm{L}$ (C) As-treated groups. Keys: (1) Cholate, (2) Isoleucine, (3) Leucine, (4) Valine, (5) Ethanol, (6) 3-Aminoisobutyrate, (7) Lactate, (8) Threonine, (9) Alanine, (10). Arginine, (11) Acetate, (12) Glutamate, (13) Glutamine, (14) Succinate, (15) Unknown 1 (2.56 ppm), (16) Aspartate, (17) Dimethylamine, (18) Asparagine, (19) Dimethylglycine, (20) Creatine phosphate, (21) Choline, (22) Phosphocholine, (23) Trimethylamine N-oxide, (24) Taurine, (25) Glycine, (26) IMP, (27) $\beta$ Glucose, (28) $\alpha$-Glucose, (29) Inosine, (30) ATP, (31) Fumarate, (32) Tyrosine, (33) Histidine and (34) Phenylalanine.

From the loading plot (Fig. 4C), the low concentration ( $5 \mu \mathrm{g} / \mathrm{L})$ of As increased the levels of dimethylamine, phosphocholine, glucose, and inosine, and decreased the levels of lactate, alanine, succinate and ATP. As shown in Fig. 4D, the high concentration $(50 \mu \mathrm{g} / \mathrm{L})$ of As induced some similar metabolic responses, including the increased phosphocholine, inosine and decreased lactate, alanine, succinate and ATP, compared with those metabolites from the low dosage group. Specifically, depleted glycine and histidine as well as increased leucine and arginine were uniquely observed in the high concentration $(50 \mu \mathrm{g} / \mathrm{L})$ of As-treated samples.

\subsection{Proteomic responses in juvenile rockfish to As exposures}

A total of 2053 proteins (homologous proteins grouped together) were identified in both As treatments (Supporting 


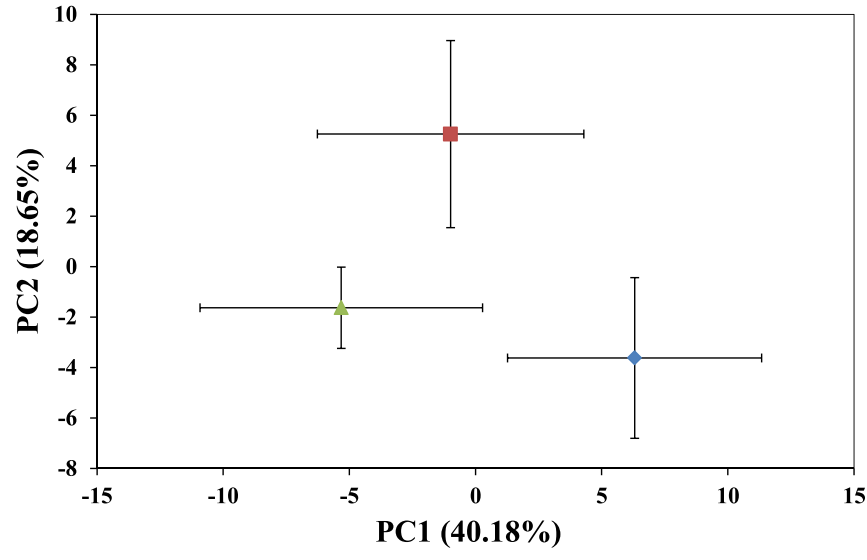

Fig. 3. Mean principal component analysis (PCA) scores plot of $\mathrm{PC} 1$ versus $\mathrm{PC} 2$ for ${ }^{1} \mathrm{H}$ NMR spectra of tissue extracts in juvenile rockfish $S$. schlegeli from control ( $\bullet), 5 \mu \mathrm{g} / \mathrm{L}$ As $(\square)$ and $50 \mu \mathrm{g} / \mathrm{L} \mathrm{As}(\Lambda)$ treatments. The classes were presented as mean \pm standard deviation of PC scores for each group of samples.

Information S2), among which 163 proteins were significantly altered. In $5 \mu \mathrm{g} / \mathrm{L}$ As-treated group, 137 proteins including 83 upregulated and 54 down-regulated proteins were found. Only 39 proteins including 22 up-regulated and 17 down-regulated proteins were found in the high concentration $(50 \mu \mathrm{g} / \mathrm{L})$ of Astreated group. The differential proteomic responses indicated that the juvenile rockfish adopted different strategies in response to As exposures at concentrations of 5 and $50 \mu \mathrm{g} / \mathrm{L}$, respectively. Among these differentially expressed proteins (DEPs), a total of 13 proteins were commonly altered in both As treatments.

All of the DEPs were classified into diverse functional classes (Fig. 5). The DEPs in the low concentration $(5 \mu \mathrm{g} / \mathrm{L})$ of As-treated group covered a wide range of metabolism (46.97\%), signal transduction (13.64\%) and cytoskeleton (12.12\%) (Fig. 5A). Meanwhile, DEPs located in the metabolism and signal transduction also constituted the majority of the altered proteins in $50 \mu \mathrm{g} / \mathrm{L}$ Astreated group, with proportions $32.26 \%$ and $29.03 \%$, respectively (Fig. 5B). The full details of the DEPs were listed in Table 1. Subsequent analyses such as GO and KEGG analyses were all based on the DEPs. Under the category of biological processes, the majority of the DEPs were related to metabolism. While under the second ontology of GO enrichment analysis-cellular components, most of the DEPs were located in the cell (35\%) and the organelle (28\%). In addition, the vast majority of DEPs were detected for catalytic activity and binding activity (Fig. 6). A total of 11 pathways were classified in the As-treated groups that shared 4 KEGG pathways, including glycolysis/gluconeogenesis, carbon metabolism, biosynthesis of amino acids and degradation of ketone bodies. The particular pathways enriched in the high concentration $(50 \mu \mathrm{g} / \mathrm{L})$ of As-treated group
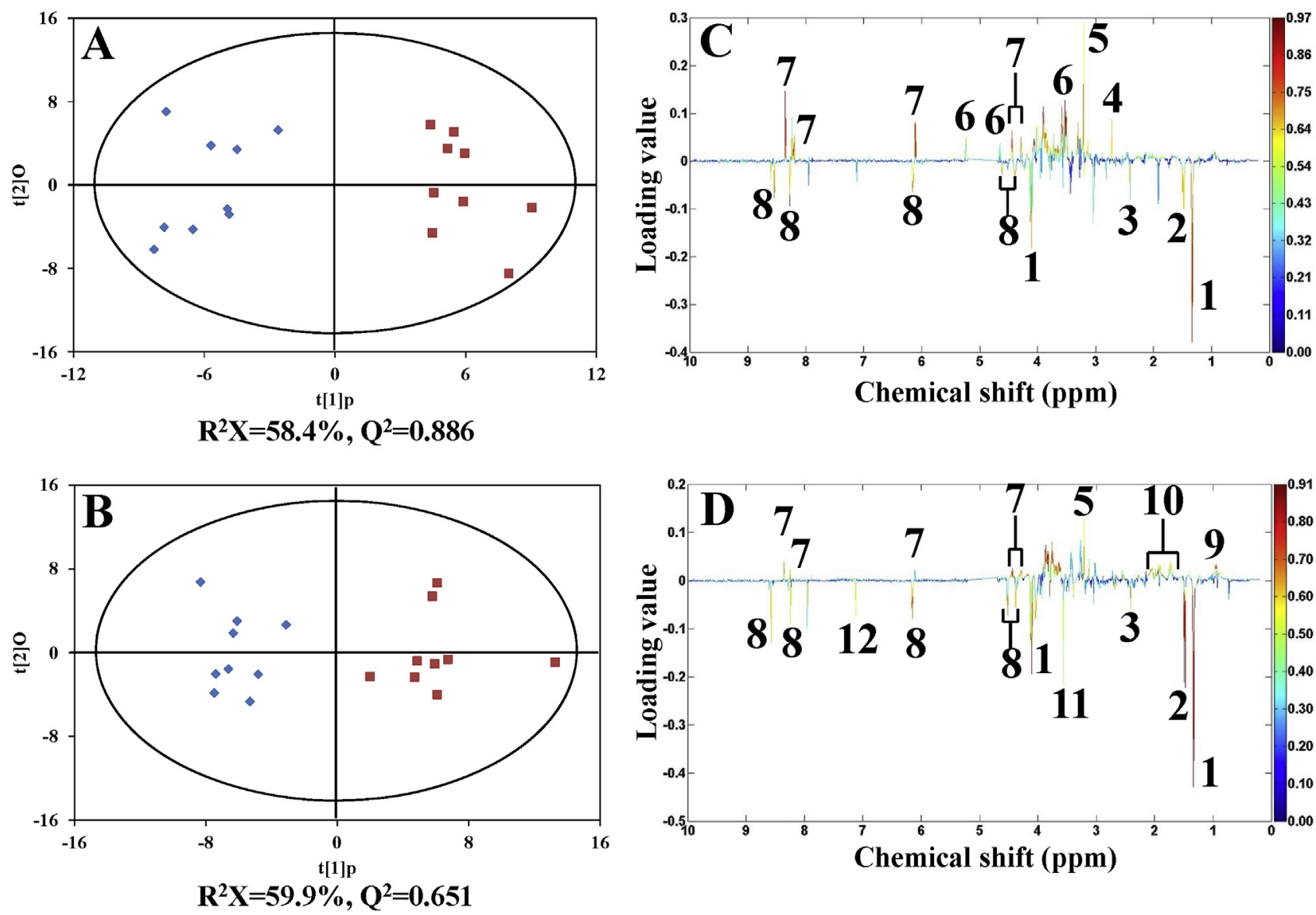

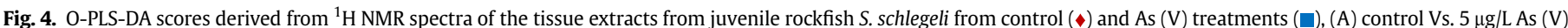

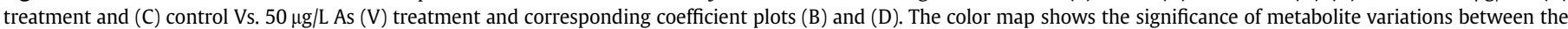

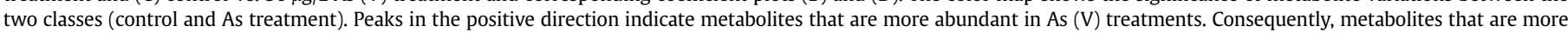

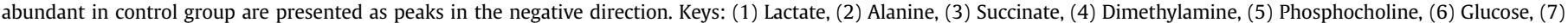

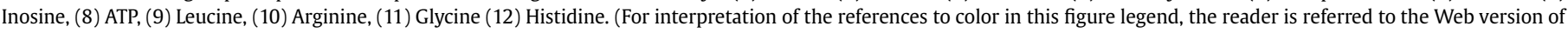
this article.) 


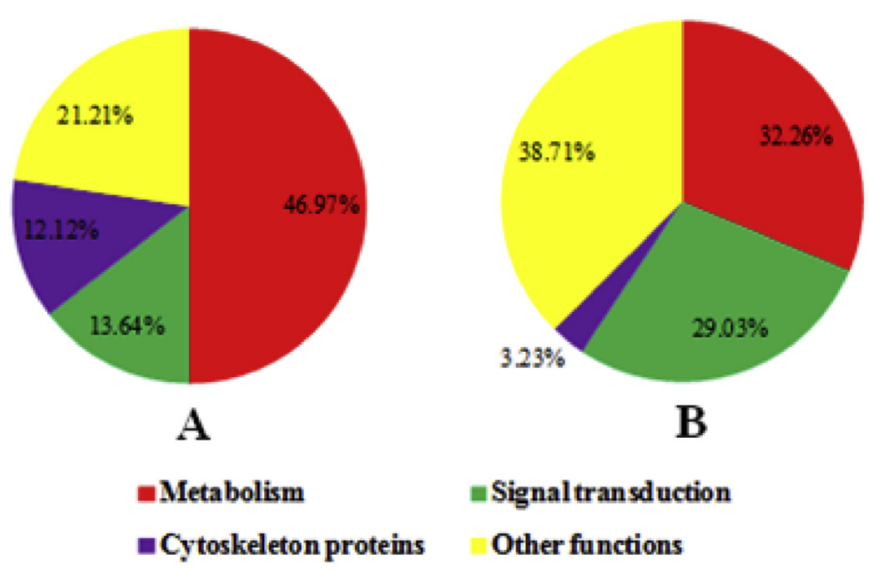

Fig. 5. Categories of DEPs of juvenile rockfish $S$. schlegeli in both As-treated groups $(5 \mu \mathrm{g} / \mathrm{L} \mathrm{As}, \mathrm{A}$ and $50 \mu \mathrm{g} / \mathrm{L} \mathrm{As}, \mathrm{B})$.

were butanoate metabolism, BACCs degradation and metabolic pathways.

\section{Discussion}

\subsection{Accumulations of As in juvenile rockfish}

In both As-treated rockfish samples, slight but significant $(p<0.05)$ accumulations of As were observed in juvenile rockfish S. schlegelii. Similarly, a slight accumulation of As was also found in the marine fish Terapon jarbua exposed to waterborne As (Zhang et al., 2012). Due to the low As bioavailability, most marine animals, such as shrimps, bivalves and fishes, have limited abilities to accumulate arsenate from seawater (Zhang et al., 2012), which was observed in juvenile rockfish $S$. schlegelii in this work. Although the average total As in the high concentration of As (50 $\mu \mathrm{g} / \mathrm{L})$-treated group was slightly higher than that in the low concentration of As $(5 \mu \mathrm{g} / \mathrm{L})$-treated group, there was no significance between these two groups. In a previous study, Kim and Kang (2015) reported that juvenile rockfish $S$. schlegelii could significantly accumulate As in some tissues, including liver, kidney, spleen, gill and intestine, in a dose-dependent manner. For the muscle tissue, however, there were only slight increases $(p>0.05)$ in As accumulations with increasing exposure concentrations from 50 to $200 \mu \mathrm{g} / \mathrm{L}$ (Kim and Kang, 2015). This was attributable to the reason that As moved into the actively main organs, such as liver, kidney, and spleen, resulting in the low As accumulation in muscle (Karaytug et al., 2007). In this work, the whole tissue of each fish individual with the muscle tissue occupying the largest proportion of tissue weight was used for experiments. Therefore, the similar As accumulations in muscle tissues might alleviate the difference of As concentrations in the whole tissues from both As-treated juvenile rockfish $S$. schlegelii. Overall, the significant accumulations of arsenic might induce toxicological effects in juvenile rockfish $S$. schlegelii.

\subsection{Alteration of glycolysis associated with As exposures}

Glycolysis can metabolize glucose into pyruvate and lactate and plays an important role in glucose metabolism (Lunt and Vander Heiden, 2011). In this work, seven proteins (glyceraldehyde-3phosphate dehydrogenase, phosphoglycerate mutase, fructosebisphosphate aldolase, glucose-6-phosphate isomerase, enolase 2, enolase 3 and L-lactate dehydrogenase A chain) related to glycolysis were identified to be differentially altered in As-treated groups. Among these proteins, only glycerol-3-phosphate dehydrogenase
(GAPDH) and phosphoglycerate mutase were commonly downregulated in both As-treated groups (Fig. 7). However, their decrements in the lower dose $(5 \mu \mathrm{g} / \mathrm{L})$ group were even greater. GAPDH is a pivotal glycolytic protein with central role in reductive force, pyruvate and energy production (Dastoor and Dreyer, 2001). Phosphoglycerate mutase is another key enzyme in glycolysis metabolism, catalyzing the conversion between 3phosphoglycerate and 2-phosphoglycerate. These two commonly altered proteins suggested that glycolysis was inhibited by both As exposures. Furthermore, the down-regulated enolase 3, L-lactate dehydrogenase A chain, fructose-bisphosphate aldolase, glucose-6phosphate isomerase and alpha-1,4 glucan phosphorylase in the low concentration of As-treated group also confirmed the inhibited glycolysis, as mentioned above. Interestingly, metabolomic analysis indicated that lactate (one of the products of glycolysis) was the most significantly decreased metabolite in both As-treated samples, followed by alanine (Fig. 4C and D). Amino acids are the major source of energy in carnivorous fish, because their natural diet is high in protein and low in carbohydrate (Waarde, 1983). Especially, alanine was demonstrated to be the single important source for de novo synthesis of glucose in the liver of migrating sockeye salmon (Oncorhynchus nerka) (French et al., 1983). Thus, the As-induced decreased lactate and alanine levels might indicate the inhibited glycolysis and the maintenance of glucose stores during As exposure. Coincidentally, the increased glucose was found exactly in the $5 \mu \mathrm{g} / \mathrm{L}$ As-treated group, which was consistent with the proteomic responses. In As-treated clam Ruditapes philippinarum, the glucose was also increased (Wu et al., 2013). Compared with As-treated clam $R$. philippinarum, however, no similar DEPs related to glycolysis were found in As-treated rockfish S. schlegelii, suggesting that As influenced glycolysis via different metabolic pathways in rockfish $S$. schlegelii and clam $R$. philippinarum. Interestingly, enolase 2 and glucose-6-phosphate isomerase in the lower As-dosed group were over expressed compared to the control. This might be a compensatory reaction to the inhibited glycolysis metabolism so as to prevent the juvenile rockfish from suffering more damage under As exposure. An earlier research revealed the enhanced glycolysis and lactate fermentation in zebrafish Danio rerio caused by arsenic exposure (15 and $20 \mathrm{ppm}$ ) (Li et al., 2016), which was partially resembled warburg effect (Reichl et al., 1988). The contrary alteration in current study might be due to the lower exposure concentrations of As ( 5 and $50 \mu \mathrm{g} / \mathrm{L}$ ). Dastoor and Dreyer (2001) reported that GAPDH could act as a nuclear repairer or a nuclear carrier of proapoptotic molecules that were associated with apoptosis and oxidative stress. In a previous work, arsenite exposure similarly down-regulated the expression levels of GAPDH in cultured lung cells (Lau et al., 2004). Therefore, the down-regulated GAPDH indicated the apoptosis or oxidative stress induced by As exposures in juvenile rockfish.

\subsection{Alteration of lipid and amino acid metabolism associated with As exposures}

Fish prefer lipids and fatty acids but carbohydrates as their sources of energy (Kullgren et al., 2010). Three altered proteins related to lipid metabolism including 3-hydroxymethyl-3methylglutaryl-CoAlyase (HMCLL1), 17-beta-hydroxysteroid dehydrogenase type 4 (HSD17B4) and fatty acid binding protein 11a (FABP11A) were identified in As-treated juvenile rockfish. HMCLL1 has important functions in lipid biosynthesis and its expression levels were the highest in both As-treated groups (Montgomery et al., 2012). HSD17B4 is indispensable in the modulation of bile acids, which is a promoter in the digestion and absorption of lipids (Mindnich et al., 2004; Chiang, 2009). This protein was uniquely up-regulated in juvenile rockfish exposed to the lower 
Table 1

The details of differentially expressed proteins (DEPs) in juvenile rockfish in response to As treatments.

\begin{tabular}{|c|c|c|c|}
\hline \multirow[t]{2}{*}{ Protein accession } & \multirow[t]{2}{*}{ Protein description } & \multicolumn{2}{|c|}{ Fold change } \\
\hline & & $5 \mu \mathrm{g} / \mathrm{L}$ As & $50 \mu \mathrm{g} / \mathrm{L} \mathrm{As}$ \\
\hline \multicolumn{4}{|c|}{ Carbohydrate Metabolism } \\
\hline Q6NV33 & Isocitrate dehydrogenase [NAD] subunit & 1.3172 & \\
\hline F1QZL6 & Glucose-6-phosphate isomerase & 1.3161 & \\
\hline Q9PVK5 & L-lactate dehydrogenase A chain (LDH-A) & 0.7464 & \\
\hline Q803Q7 & Fructose-bisphosphate aldolase & 0.7431 & \\
\hline F1QBW7 & Enolase 1, (Alpha) (Enolase 3) & 0.6962 & \\
\hline Q503C7 & Alpha-1,4 glucan phosphorylase & 0.6868 & \\
\hline Q6GQM9 & Eno2 protein (Enolase 2 ) & 1.5375 & \\
\hline Q7SY54 & Ethanolamine-phosphate phospho-lyase & 1.4057 & \\
\hline Q5XJ10 & Glyceraldehyde-3-phosphate dehydrogenase & 0.5768 & 0.7164 \\
\hline B8A4H6 & Phosphoglycerate mutase & 0.623 & 0.6681 \\
\hline \multicolumn{4}{|c|}{ Amino Acid Metabolism } \\
\hline Q6PHK4 & Serine-pyruvate aminotransferase & 1.7514 & \\
\hline F1Q740 & Valyl-tRNA synthetase & 0.6904 & \\
\hline Q6DC37 & Histamine N-methyltransferase (HMT) & 0.6863 & \\
\hline \multicolumn{4}{|l|}{ Lipid Metabolism } \\
\hline Q66I80 & Fatty acid binding protein $11 \mathrm{a}$ & 0.7656 & \\
\hline Q8AYH1 & 17-beta-hydroxysteroid dehydrogenase type 4 & 1.3922 & \\
\hline A2BGU5 & Low density lipoprotein receptor-related protein & & 1.3382 \\
\hline A8WG57 & 3-hydroxymethyl-3-methylglutaryl-CoA lyase & 2.3496 & 1.7554 \\
\hline \multicolumn{4}{|l|}{ Protein Metabolism } \\
\hline Q8JGR4 & $60 S$ ribosomal protein $\mathrm{L} 24$ & 1.3614 & \\
\hline Q5BJJ2 & Ribosomal protein L3 (Rpl3 protein) & 0.7254 & \\
\hline Q7ZV82 & 60 S ribosomal protein $\mathrm{L} 27$ & & 0.7551 \\
\hline F1Q845 & Metalloendopeptidase & 0.7335 & 0.7688 \\
\hline \multicolumn{4}{|c|}{ Mitochondrial Energy Metabolism } \\
\hline Q6PBX8 & NADH dehydrogenase (ubiquinone) flavoprotein 2 & 1.3056 & \\
\hline Q6ZM23 & Cytochrome $c$ oxidase subunit VIc & 1.3646 & \\
\hline Q3B750 & Cytochrome $b-c 1$ complex subunit 6 & 1.4299 & \\
\hline A2ARG7 & ATP synthase, $\mathrm{H}^{+}$-transporting & 1.6696 & \\
\hline Q6TNV0 & Cytochrome $c$ oxidase subunit 4 isoform 1 & 1.6218 & 1.3438 \\
\hline \multicolumn{4}{|l|}{ Other Metabolism } \\
\hline Q6P2U5 & ADP-ribosylation factor $6 a$ & 1.3459 & \\
\hline A9C3S0 & Si:ch211-198n5.11 & 0.7469 & \\
\hline Q5RGV1 & Inosine-5'-monophosphate dehydrogenase $1 \mathrm{~b}$ & 1.5453 & \\
\hline Q6P3G5 & AMP deaminase (EC 3.5.4.6) & 0.7638 & \\
\hline F1RCB2 & DEAD (Asp-Glu-Ala-Asp) box helicase 3b & 0.5542 & 0.6721 \\
\hline F8W4R3 & Adenine phosphoribosyltransferase & 2.0204 & 1.5965 \\
\hline F1R1J6 & Paxillin a (Fragment) & 1.8103 & 1.3608 \\
\hline \multicolumn{4}{|l|}{ Signal Transduction } \\
\hline Q7ZUR5 & Signal sequence receptor, gamma & 1.5329 & \\
\hline Q5XJS6 & PRA1 family protein & 1.4168 & \\
\hline E9QCG6 & Collagen, type I, alpha 2 & 1.3861 & \\
\hline Q08BI9 & Calcium uniporter protein, mitochondrial & 1.3454 & \\
\hline Q7T2E3 & Casein kinase I isoform delta-A & 1.3176 & \\
\hline C7DZK3 & Collagen alpha-1 (XXVII) chain A & 1.3127 & \\
\hline Q6ZM60 & Calcium-transporting ATPase (EC 3.6.3.8) & 0.6739 & \\
\hline F1QDL1 & Collagen, type I, alpha 1b & & 1.3121 \\
\hline F1QI59 & Serine/threonine-protein phosphatase (EC 3.1.3.16) & & 1.3163 \\
\hline Q5TZF1 & Voltage-dependent L-type calcium channel subunit alpha & & 1.355 \\
\hline Q503E2 & Prolyl endopeptidase (Zgc:110670) & & 1.4001 \\
\hline F1QJC9 & Collagen, type I, alpha $1 \mathrm{a}$ & & 1.4004 \\
\hline Q7ZV37 & Protein phosphatase methylesterase 1 & & 1.5422 \\
\hline F1Q6E0 & Protein tyrosine phosphatase, receptor type, $\mathrm{U}, \mathrm{a}$ & 1.5025 & 1.7454 \\
\hline Q6TNT8 & Guanine nucleotide binding protein & 1.7018 & 0.7405 \\
\hline Cytoskeleton Prote & & & \\
\hline F1QWU4 & Myosin, light chain 6 & 1.6702 & \\
\hline P13104 & Tropomyosin alpha-1 chain (Alpha-tropomyosin) & 1.3689 & \\
\hline Q66I73 & Myosin light chain, phosphorylatable, fast skeletal muscle b & 1.3226 & \\
\hline Q6ZM50 & Capping protein (actin filament) muscle Z-line, alpha $1 \mathrm{~b}$ & 1.5122 & \\
\hline E7EYD0 & Myomesin 1a (skelemin) & 0.741 & \\
\hline B0UY61 & Nebulin & 0.7276 & \\
\hline F1R6C7 & Myosin, heavy chain a & 0.6928 & \\
\hline A0JMF4 & Septin 15 (Septin 7b) & 0.6733 & \\
\hline F1QK60 & Keratin 4 & 1.7569 & 1.3273 \\
\hline Other Function & & & \\
\hline Q9I8U7 & Fast skeletal muscle myosin light polypeptide 3 & 1.5569 & \\
\hline F1QI24 & Zgc:55262 & 1.5051 & \\
\hline Q7T339 & Charged multivesicular body protein 5 & 1.3822 & \\
\hline Q5RGU1 & Atypical kinase COQ8A, mitochondrial & 1.3682 & \\
\hline Q7ZTY5 & Eukaryotic translation initiation factor $2 \mathrm{~B}$, subunit 3 gamma & 1.3511 & \\
\hline Q5XJA3 & Protein PRRC1 & 1.3286 & \\
\hline F1R212 & Fas (TNFRSF6)-associated factor 1 & 1.316 & \\
\hline
\end{tabular}


Table 1 (continued)

\begin{tabular}{|c|c|c|c|}
\hline \multirow[t]{2}{*}{ Protein accession } & \multirow[t]{2}{*}{ Protein description } & \multicolumn{2}{|c|}{ Fold change } \\
\hline & & $5 \mu \mathrm{g} / \mathrm{L}$ As & $50 \mu \mathrm{g} / \mathrm{L}$ As \\
\hline Q7ZVY0 & Cytotoxic granule-associated RNA binding protein 1 & 0.7579 & \\
\hline Q0ZBR7 & Macrophage migration inhibitory factor & 0.7537 & \\
\hline Q9DDU5 & Glutathione S-transferase pi & 0.7505 & \\
\hline Q6IMW7 & Parvalbumin 4 (Pvalb4 protein) & 0.7457 & \\
\hline F1QYE2 & Tenascin C & 0.6738 & \\
\hline F1R968 & Complement component 1 , q subcomponent-binding protein & & 1.3176 \\
\hline B8JI86 & Tripartite motif-containing 63b & & 0.7382 \\
\hline A6NA21 & Polymerase I and transcript release factor & & 1.3567 \\
\hline F1R2T2 & Fras1-related extracellular matrix 1b & & 1.3677 \\
\hline Q7SZY8 & Glyoxylate reductase & & 0.7513 \\
\hline Q24JW2 & Lysozyme (EC 3.2.1.17) & & 0.7342 \\
\hline B0R174 & Retinol-binding protein $1 \mathrm{~b}$, cellular & & 0.7287 \\
\hline Q7ZUP0 & Acidic leucine-rich nuclear phosphoprotein 32 family member $A$ & & 0.7044 \\
\hline Q6NSP1 & Adaptor-related protein complex 1 & & 0.6885 \\
\hline Q08CK7 & Insulin-like growth factor 2 mRNA-binding protein 1 & & 1.3361 \\
\hline F1QRU6 & Chloride intracellular channel protein (Fragment) & 0.6653 & 0.6433 \\
\hline Q6NYD2 & Sideroflexin (Fragment) & 2.2156 & 1.391 \\
\hline
\end{tabular}

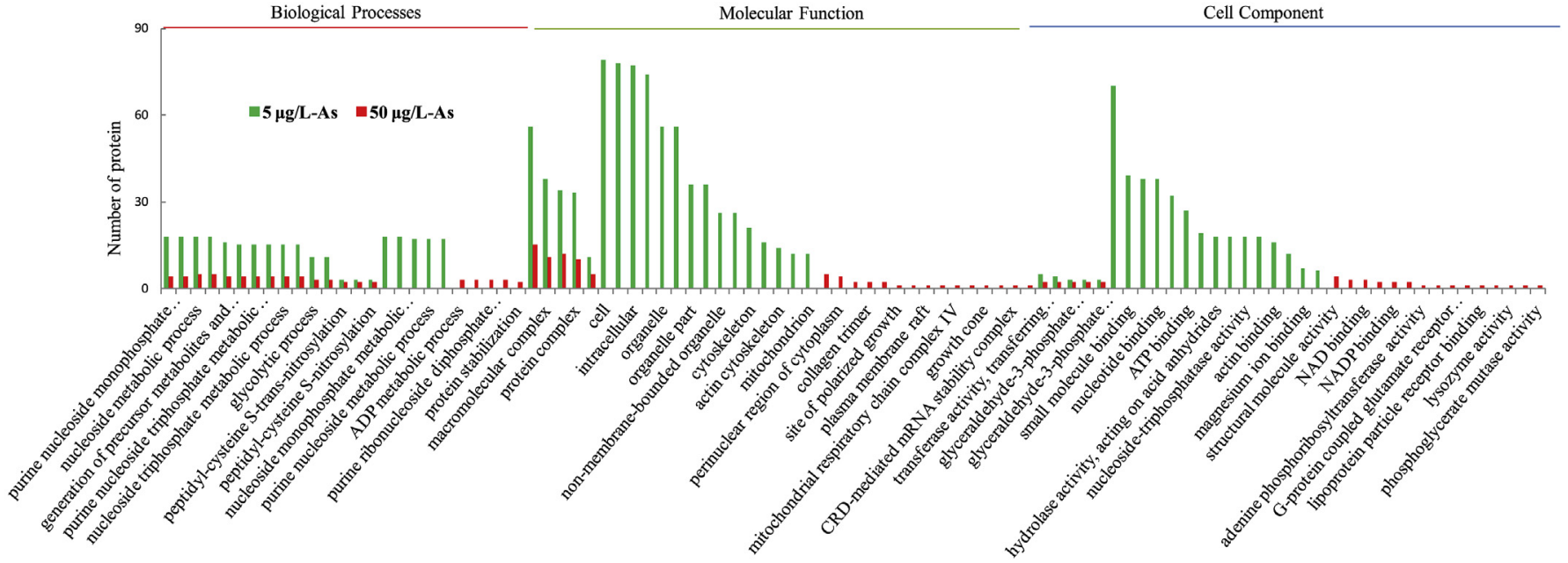

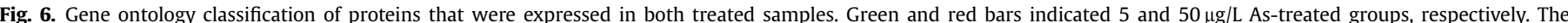

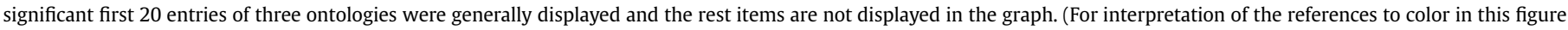
legend, the reader is referred to the Web version of this article.)

concentration of As. These DEPs indicated that juvenile rockfish facilitated their lipid regulation in response to As exposure so as to ensure the energy supply. Strangely, the FABP11A was downregulated slightly (0.76-fold) in the juvenile rockfish exposed to the low concentration of As. As a member of FABP family, FABP11A primarily functions in regulation of fatty acid uptake and intracellular transport. Previous studies demonstrated that the members of the FABP family functioned as modulation of cell growth and proliferation (Chmurzyńska, 2006). Therefore, the down-regulation of FABP11A suggested that As might disturb cell growth and proliferation in juvenile rockfish.

Perturbed amino acid metabolism has been reported in fishes exposed to As (Kumari et al., 2017; Li et al., 2016; Palaniappan and Vijayasundaram, 2009). In As-treated zebrafish, the levels of some amino acids (threonine, glycine, etc.) were reduced, which was related to dysfunctional energy metabolism (Li et al., 2016). However, Palaniappan and Vijayasundaram (2009) found that As exposure might reduce protein synthesis and increase amino acids in freshwater fingerlings Labeo rohita. In this work, the amino acids, arginine and leucine, were significantly increased, while alanine, glycine and histidine were decreased in either low or high concentration of As-treated juvenile rockfish, indicated by metabolomic analysis (Fig. 4C and D). The amino acids are essential for energy production via TCA cycle (Sears et al., 2009), suggesting the dysfunctional energy metabolism induced by As in juvenile rockfish, together with the altered metabolites (succinate and ATP) involved in energy metabolism. The enzyme, asparagine synthetase (ASNS), catalyzes the biosynthesis of asparagine through an ATPdependent reaction using glutamine as a source of nitrogen (Zalkin, 1993). The ASNS in the low concentration $(5 \mu \mathrm{g} / \mathrm{L})$ of Astreated group was down-regulated. In addition, amino acid metabolism is involved protein synthesis, as mentioned above. Ribosomal proteins perform the crucial function of protein biosynthesis (Ruszczyk et al., 2008). The altered levels of ribosomal proteins (RPL24, RPL3 and RPL27) were accordingly observed in the Astreated samples. Since aminoacyl-tRNA plays a critical role in ribosomal protein synthesis by transporting amino acid, the downregulated valyl-tRNA synthetase (VARS), combined with the down-regulated ASNS and altered composition of ribosomal proteins, indicated the disturbances in protein synthesis/degradation 

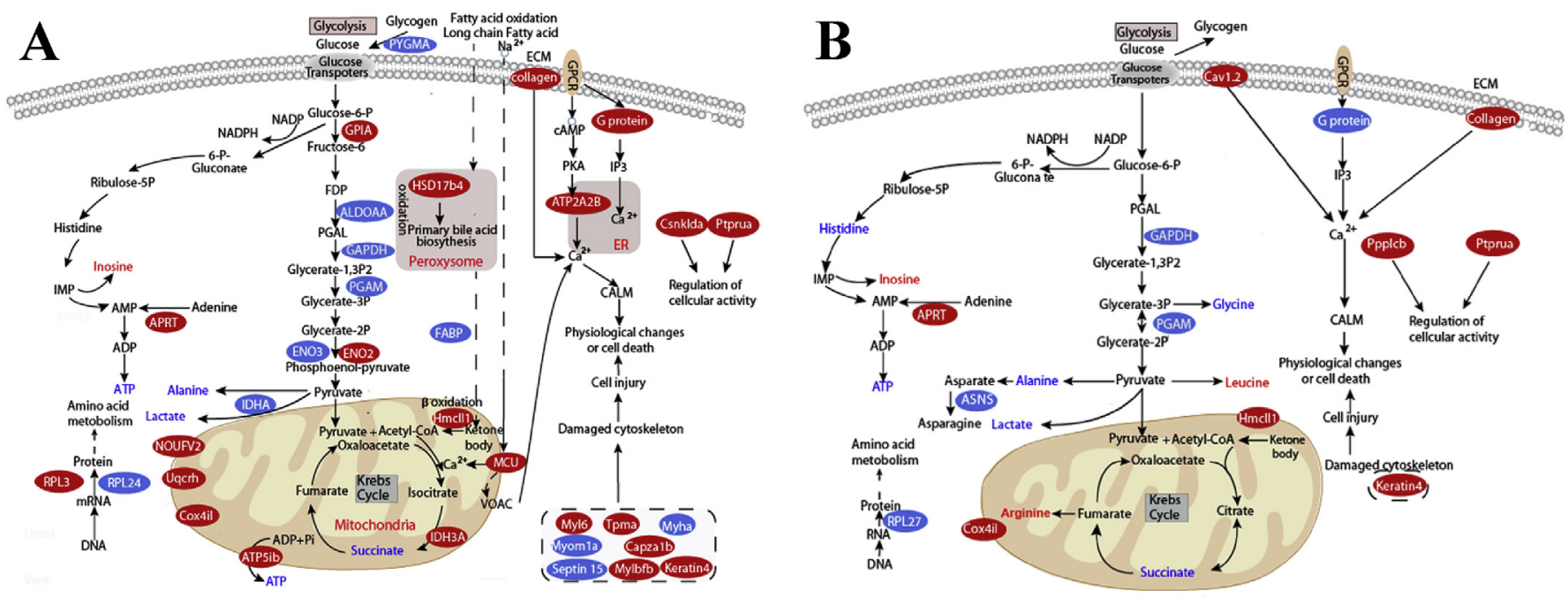

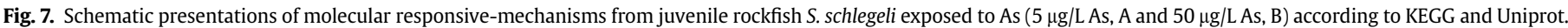

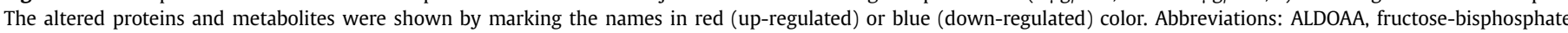

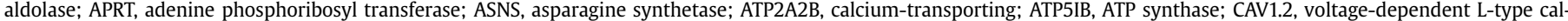

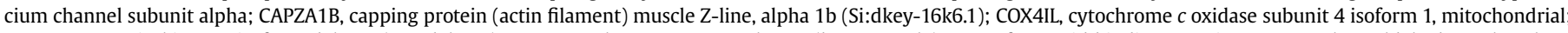

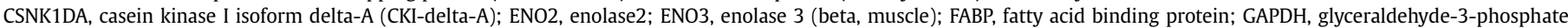

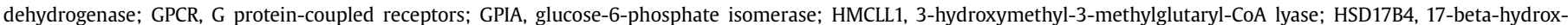

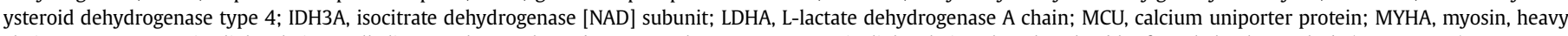

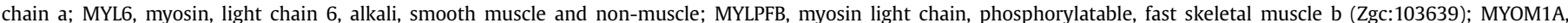

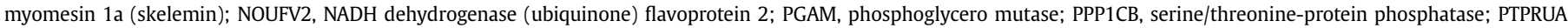

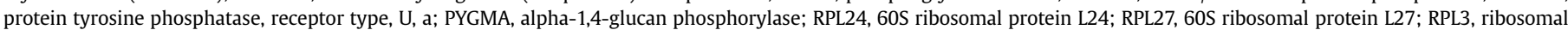

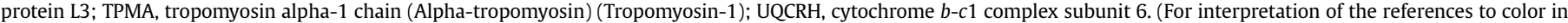
this figure legend, the reader is referred to the Web version of this article.)

processes as well (He et al., 2013).

\subsection{Alteration of mitochondrial energy metabolism associated with As exposures}

Mitochondria are involved in the regulation of energy metabolism and $95 \%$ of the energy required for cell survival is provided by the mitochondrial respiratory chain which is the main site of oxidative phosphorylation and ATP synthesis. The respiratory chain or electron transport chain (ETC) locates within the inner membrane of mitochondria, and consists of NADH ubiquinone oxidoreductase (Complex I), succinate ubiquinone oxidoreductase (SQR) (Complex II), ubiquinone-cytochrome c reductase (QCR) (Complex III), cytochrome oxidase (COX) (Complex IV) and the $\mathrm{F}_{1} \mathrm{~F}_{0}$-ATP synthase. In this study, one of the most remarkable changes associated with As stress was the up-regulation of proteins related to oxidative phosphorylation and ATP synthesis. Expressions of cytochrome $c$ oxidase subunit 4 (COX4) were up-regulated in juvenile rockfish exposed to both As treatments (1.62- and 1.34-fold, respectively). NADH dehydrogenase (ubiquinone) flavoprotein 2 (NDUFV2), cytochrome $c$ oxidase subunit VIc (COX6C), cytochrome $b-c 1$ complex subunit 6 (UQCRH) and ATP synthase F0 complex were also up-regulated compared with those in control group. Rezin et al. (2008) reported the dysregulation of mitochondrial respiratory chain complex proteins in rat models exposed to chronic stress such as food deprivation, isolation and flashing light. These up-regulated proteins suggested a disturbance of the mitochondrial respiratory chain in juvenile rockfish. One previous study reported that increased oxidative phosphorylation might be an adaptive and protective mechanism in coping with external pressures (Bisgaard et al., 2007). For this reason, the disturbance of the mitochondrial respiratory chain in juvenile rockfish revealed an energetic readjustment process in fighting against As stress. Moreover, adenine phosphoribosyltransferase (APRT) was found to be over expressed dramatically in both As-treated groups. APRT has the function of promoting the biosynthesis of ATP through a salvage reaction leading to the formation of AMP (Shao et al., 2015). In addition, isocitrate dehydrogenase is an indispensable enzyme of the Krebs cycle. Thus the up-regulated isocitrate dehydrogenase in $5 \mu \mathrm{g} / \mathrm{L}$ As treaded-group combined with the altered APRT in both As-treated groups indicated that juvenile rockfish underwent disturbance in energy metabolism. Furthermore, the elevated ADP/ ATP concentration ratios could stimulate the activity of isocitrate dehydrogenase (Denton and Mccormack, 1980). Therefore, the upregulation of isocitrate dehydrogenase meant the possible depletion of ATP, which was clearly detected in the metabolic profiles from As-exposed juvenile rockfish samples (Fig. 4C and D). The coherence between metabolomic and proteomic biomarkers suggested the complementarity between proteomics and metabolomics in toxicological biomarker discovery. In As-exposed clam R. philippinarum, the contrary metabolic alterations compared with these in As-exposed rockfish S. schlegelii, including depleted succinate and elevated ATP, were observed (Wu et al., 2013). These differences revealed species-specific strategies in energy metabolism in rockfish and clam to As exposure. In addition, NDUFV2 is an important subunit of the NADH dehydrogenase, which is involved in production of reactive oxygen species (ROS) in mitochondria (Turrens and Boveris, 1980). The increased expression of NDUFV2 implied that juvenile rockfish suffered from clear oxidative stress under As $(5 \mu \mathrm{g} / \mathrm{L})$ exposure. Apparently, isocitrate dehydrogenase can also take part in redox reaction by producing NADH. The up-regulation of isocitrate dehydrogenase was in conformity with the over expressed NDUFV2, suggesting the oxidative stress induced by As $(5 \mu \mathrm{g} / \mathrm{L})$ treatment in juvenile rockfish.

\subsection{Alteration of signal transduction associated with As exposures}

In juvenile rockfish samples from both As-treated groups, four 
collagens were up-regulated with statistical significances. Collagens are not only responsible for the resilience of multicellular organism and mechanical resistance, but also participate in signaling pathways of defining cellular shape and behavior (Daley et al., 2008). The altered collagens suggested the disruption in signaling pathways via the extracellular matrix in juvenile rockfish induced by As. $\mathrm{Ca}^{2+}$ is a highly versatile intracellular signal that can regulate many different cellular functions (Carafoli et al., 2001). In this work, calcium uniporter protein was significantly up-regulated and calcium-transporting ATPase was significantly down-regulated in $5 \mu \mathrm{g} / \mathrm{L}$ As-treated group (Table 1). In addition, as one subtype of voltage-gated calcium channels in cytomembrane, voltagedependent L-type calcium channel subunit alpha was significantly up-regulated in $50 \mu \mathrm{g} / \mathrm{L}$ As-treated group. These altered proteins implied the disturbed calcium homeostasis in juvenile rockfish exposed to As. G proteins are not only involved in signaling pathways but also critical for stress responses (Clapham and Neer, 1993). The significant alteration of $G$ protein implied the cellular injury induced by As exposure. CK1 protein kinases belong to a large family of Ser/Thr kinases in eukaryotes that can be used to regulate diverse cellular processes and coordinate in an orderly manner through different signal transduction pathways (Gross and Anderson, 1998; Knippschild et al., 2005). Serine/threonine-protein phosphatases and tyrosine protein phosphatase belong to protein phosphatases family with the functions of regulating various cellular processes through different signaling pathways (Tian and Wang, 2002). Increased abundances of CK1 protein kinases and serine/threonine-protein phosphatases were detected in low $(5 \mu \mathrm{g} /$ L) and high $(50 \mu \mathrm{g} / \mathrm{L})$ concentrations of As-treated groups, respectively. Moreover, tyrosine protein phosphatase significantly increased its protein abundance in both As-treated groups. These altered proteins suggested the disturbance of signaling pathways in juvenile rockfish exposed to As.

\subsection{Cytoskeleton changes induced by As}

A total of eight proteins related to cytoskeleton were altered in the As-treated samples. Keratin 4 was commonly expressed in both As-exposed groups. The other seven proteins (myosin light chain 6 , tropomyosin alpha-1 chain, myosin light chain, myomesin 1a, myosin heavy chain a, septin 15 , mapping protein (actin filament) muscle Z-line) were uniquely detected in the low dose of Asexposed group. The cytoskeleton proteins have the central role in cell structure and intracellular organization and perturbations in the architecture of any of the three main cytoskeletal networks can result in marked pathologies (Fletcher and Mullins, 2010). Metals or metalloids can induce cytoskeletal injuries in marine bivalves, which has been confirmed in both laboratory and field experiments by proteomics (Wu et al., 2013; Xu et al., 2016). The DEPs related to cytoskeletal injuries usually include actins, tubulins and myosin light chains in marine bivalves (clam $R$. philippinarum and oyster Crassostrea hongkongensis), which were also observed in As-treated rockfish in this work. Therefore, the alterations of these eight cytoskeleton-associated proteins suggested the cytoskeleton injuries induced by As exposures in juvenile rockfish.

\section{Conclusions}

In this study, the toxicological effects were characterized in juvenile rockfish $S$. schlegelii exposed to As with environmentally relevant concentrations ( 5 and $50 \mu \mathrm{g} / \mathrm{L}$ ) of As (V) for 14 days, at metabolite and protein levels. A schematic illustration of pathways in juvenile rockfish exposed to As (V) was presented in Fig. 7. Combined proteomic and metabolomic analyses showed that As significantly influenced diverse biological processes in juvenile rockfish, such as glycolysis, mitochondrial energy metabolism, lipid and amino acid metabolisms and the regulation of $\mathrm{Ca}^{2+}$ signaling pathways in juvenile rockfish. Although these two dosages of As induced some similar effects in juvenile rockfish S. schlegelii, the distinction between these two As treatments were also clearly observed from the metabolomic and proteomic profiles. Especially, more DEPs were altered in the low concentration $(5 \mu \mathrm{g} / \mathrm{L})$ of Astreated group, which suggested that the low dose of As could activate physiological changes in juvenile rockfish to counteract the adverse situation, while the high dose of As $(50 \mu \mathrm{g} / \mathrm{L})$ induced an evasion from the stressful situation. This study demonstrated that the combined proteomic and metabolomic analysis could provide a perceptive view into the influences of environmental metal pollution in the marine fish at molecular levels.

\section{Ethical statement}

All procedures were strictly performed according to the Guidelines of the Chinese Council on Laboratory Animal Care (2011), which was approved by the Animal Research Ethics Board of Chinese Academy of Sciences.

\section{Declaration of competing interest}

We declare that we do not have any commercial or associative interest that represents a conflict of interest in connection with the work submitted.

\section{Acknowledgments}

This research was supported by NSFC (41676114), the Young Taishan Scholars Program of Shandong Province for Prof. Huifeng Wu (tsqn201812115), Qingdao National Laboratory for Marine Science and Technology (QNLM201701) and Youth Innovation Promotion Association CAS (2015169).

\section{Appendix A. Supplementary data}

Supplementary data to this article can be found online at https://doi.org/10.1016/j.envpol.2019.113333.

\section{References}

Bisgaard, C.F., Jayatissa, M.N., Enghild, J.J., Sanchéz, C., Artemychyn, R., 2007. Proteomic investigation of the ventral rat hippocampus links DRP-2 to escitalopram treatment resistance and SNAP to stress resilience in the chronic mild stress model of depression. J. Mol. Neurosci. 32, 132-144.

Brandão, F., Cappello, T., Raimundo, J., Santos, M.A., Maisano, M., Mauceri, A. Pacheco, M., Pereira, P., 2015. Unravelling the mechanisms of mercury hepatotoxicity in wild fish (Liza aurata) through a triad approach: bioaccumulation, metabolomic profiles and oxidative stress. Metallomics 7, 1352-1363.

Cappello, T., Brandão, F., Guilherme, S., Santos, M.A., Maisano, M., Mauceri, A., Canário, J., Pacheco, M., Pereira, P., 2016a. Insights into the mechanisms underlying mercury-induced oxidative stress in gills of wild fish (Liza aurata) combining ${ }^{1} \mathrm{H}$ NMR metabolomics and conventional biochemical assays. Sci. Total Environ. 548-549, 13-24.

Cappello, T., Pereira, P., Maisano, M., Mauceri, A., Pacheco, M., Fasulo, S., 2016b. Advances in understanding the mechanisms of mercury toxicity in wild golden grey mullet (Liza aurata) by ${ }^{1} \mathrm{H}$ NMR-based metabolomics. Environ. Pollut. 139-148.

Carafoli, E., Santella, L., Branca, D., Brini, M., Carafoli, E., Santella, L., Branca, D. Brini, M., 2001. Generation, control, and processing of cellular calcium signals. Crit. Rev. Biochem. Mol. Biol. 36, 107-260.

Chen, D., Ye, Z., Duan, Y., Feng, D., 1994. Preliminary studies on the biology of reproduction groups and the fry breeding in black rockfish Sebastes schlegelii. Acta Oceanol. Sin. 16, 94-101 (in Chinese).

Chen, H., Diao, X., Wang, H., Zhou, H., 2018a. An integrated metabolomic and proteomic study of toxic effects of Benzo[a]pyrene on gills of the pearl oyster Pinctada martensii. Ecotoxicol. Environ. Saf. 156, 330-336.

Chen, L., Song, D., Zhang, W., Zhang, C., Zhang, L., 2019. The dynamic changes of arsenic bioaccumulation and antioxidant responses in the marine medaka 
Oryzias melastigma during chronic exposure. Aquat. Toxicol. 212, 110-119.

Chen, L., Zhang, W., Guo, Z., Zhang, L., 2018b. Effects of acclimation on arsenic bioaccumulation and biotransformation in freshwater medaka Oryzias mekongensis after chronic arsenic exposure. Environ. Pollut. 238, 17-15.

Chen, L., Hu, Y., He, J., Chen, J., Giesy, J.P., Xie, P., 2017. Responses of the proteome and metabolome in livers of zebra fish exposed chronically to environmentally relevant concentrations of microcystin-LR. Environ. Sci. Technol. 51, 596-607.

Chiang, J.Y.L., 2009. Bile acids: regulation of synthesis. J. Lipid Res. 50, 1955-1966.

Chmurzyńska, A., 2006. The multigene family of fatty acid-binding proteins (FABPs): function, structure and polymorphism. J. Appl. Genet. 47, 39-48.

Clapham, D.E., Neer, E.J., 1993. New roles for G-protein $\beta \gamma$-dimers in transmembrane signalling. Nature 365, 403-406.

Daley, W.P., Peters, S.B., Larsen, M., 2008. Extracellular matrix dynamics in development and regenerative medicine. J. Cell Sci. 121, 255-264.

Dastoor, Z., Dreyer, J.L., 2001. Potential role of nuclear translocation of glyceraldehyde-3-phosphate dehydrogenase in apoptosis and oxidative stress. J. Cell Sci. $114,1643-1653$.

Denton, R.M., Mccormack, J.G., 1980. The role of calcium in the regulation of mitochondrial metabolism. Biochem. Soc. Trans. 8, 266-268.

Erickson, R.J., Mount, D.R., Highland, T.L., Hockett, J.R., Hoff, D.J., Jenson, C.T. Lahren, T.J., 2019. The effects of arsenic speciation on accumulation and toxicity of dietborne arsenic exposures to rainbow trout. Aquat. Toxicol. 210, 227-241.

Fletcher, D.A., Mullins, R.D., 2010. Cell mechanics and the cytoskeleton. Nature 463, 485-492.

French, C.J., Hochachka, P.W., Mommsen, T.P., 1983. Metabolic organization of liver during spawning migration of sockeye salmon. Am. J. Physiol. Regul. Integr. Comp. Physiol. 245, R827-R830.

Gao, X., Zhou, F., Chen, C.T.A., 2014. Pollution status of the Bohai Sea: an overview of the environmental quality assessment related trace metals. Environ. Int. 62, $12-30$.

García-Sevillano, M.A., Jara-Biedma, R., González-Fernández, M., García-Barrera, T., Gómez-Ariza, J.L., 2013. Metal interactions in mice under environmental stress. Biometals 26, 651-666.

Garg, S., Gupta, R.K., Jain, K.L., 2008. Sub-lethal effects of heavy metals on biochemical composition and their recovery in Indian major carp. J. Hazard Mater. 163, 1369-1384.

Gross, S.D., Anderson, R.A., 1998. Casein kinase I: spatial organization and of a multifunctional protein kinase family. Cell. Signal. 10, 699-711.

Han, Z., Sun, J., Zhang, Y., He, F., Xu, Y., Matsumura, K., He, L.S., Qiu, J.W., Qi, S.H., Qian, P.Y., 2013. iTRAQ-based proteomic profiling of the barnacle Balanus amphitrite in response to the antifouling compound meleagrin. J. Proteome Res. $12,2090-2100$

He, Y., Dai, S., Dufresne, C.P., Zhu, N., Pang, Q., Chen, S., 2013. Integrated proteomics and metabolomics of arabidopsis acclimation to gene-dosage dependent perturbation of isopropylmalate dehydrogenases. PLoS One 8, e57118.

Isaacson, T., Damasceno, C.M.B., Saravanan, R.S., He, Y., Catalá, C., Saladié, M., Rose, J.K.C., 2006. Sample extraction techniques for enhanced proteomic analysis of plant tissues. Nat. Protoc. 1, 769-774.

Ji, C., Lu, Z., Xu, L., Li, F., Cong, M., Shan, X., Wu, H., 2019. Evaluation of mitochondrial toxicity of cadmium in clam Ruditapes philippinarum using iTRAQ-based proteomics. Environ. Pollut. 251, 802-810.

Ji, C., Wu, H., Wei, L., Zhao, J., 2014. iTRAQ-based quantitative proteomic analyses on the gender-specific responses in mussel Mytilus galloprovincialis to tetrabromobisphenol A. Aquat. Toxicol. 157, 30-40.

Ji, C., Xu, H., Wang, Q., Zhao, J., Wu, H., 2015. Comparative investigations on the biological effects of as (III) and as (V) in clam Ruditapes philippinarum using multiple biomarkers. Fish Shellfish Immunol. 47, 79-84.

Jones, O., Dondero, F., Viarengo, A., Griffin, J., 2008. Metabolic profiling of Mytilus galloprovincialis and its potential applications for pollution assessment. Mar. Ecol. Prog. Ser. 369, 169-179.

Karaytug, S., Erdem, C., Cicik, B., 2007. Accumulation of cadmium in the gill, liver kidney, spleen, muscle and brain tissues of Cyprinus carpio. Ekoloji 16, 16-22.

Kim, J.H., Kang, J.C., 2017. Effects of sub-chronic exposure to lead (Pb) and ascorbic acid in juvenile rockfish: antioxidant responses, MT gene expression, and neurotransmitters. Chemosphere 171, 520-527.

Kim, J.H., Kang, J.C., 2015. The arsenic accumulation and its effect on oxidative stress responses in juvenile rockfish, sebastes schlegelii, exposed to waterborne arsenic $\left(\mathrm{As}^{3+}\right)$. Environ. Toxicol. Pharmacol. 39, 668-676.

Knippschild, U., Gocht, A., Wolff, S., Huber, N., Löhler, J., Stöter, M., 2005. The casein kinase 1 family: participation in multiple cellular processes in eukaryotes. Cell. Signal. 17, 675-689.

Kreppel, H., Bauman, J.W., Liu, J., McKim, J.M., Klaassen, C.D., 1993. Induction of metallothionein by arsenicals in mice. Fundam. Appl. Toxicol. 20, 184-189.

Kullgren, A., Samuelsson, L.M., Larsson, D.G.J., Björnsson, B.T., Bergman, E.J., 2010. A metabolomics approach to elucidate effects of food deprivation in juvenile rainbow trout (Oncorhynchus mykiss). J. Physiol. Regul. Integr. Comp. Physiol. 299, R1440-R1448.

Kumari, B., Kumar, V., Sinha, A.K., Ahsan, J., Ghosh, A.K., Wang, H., DeBoeck, G., 2017. Toxicology of arsenic in fish and aquatic systems. Environ. Chem. Lett. 15, 43-64.

Lau, A.T.Y., He, Q.Y., Chiu, J.F., 2004. A proteome analysis of the arsenite response in cultured lung cells: evidence for in vitro oxidative stress-induced apoptosis. Biochem. J. 382, 641-650.

Lee, E., Kim, M., Moon, Y., Hyuk, U., Yong, S., 2018. Adverse effects and immune dysfunction in response to oral administration of weathered Iranian heavy crude oil in the rockfish Sebastes schlegeli. Aquat. Toxicol. 200, 127-135.

Li, C., Li, P., Tan, Y.M., Lam, S.H., Chan, E.C.Y., Gong, Z., 2016. Metabolomic characterizations of liver injury caused by acute arsenic toxicity in zebrafish. PLoS One $11,1-18$.

Li, H., Gao, X., Gu, Y., Wang, R., Xie, P., Liang, M., Ming, H., 2018. Comprehensive large-scale investigation and assessment of trace metal in the coastal sediments of Bohai Sea. Mar. Pollut. Bull. 129, 126-134.

Lin, C.Y., Wu, H., Tjeerdema, R.S., Viant, M.R., 2007. Evaluation of metabolite extraction strategies from tissue samples using NMR metabolomics. Metabolomics 3, 55-67.

Liu, X., Zhang, L., You, L., Yu, J., Zhao, J., Li, L., Wang, Q., Li, F., Li, C., Liu, D., Wu, H., 2011. Differential toxicological effects induced by mercury in gills from three pedigrees of Manila clam Ruditapes philippinarum by NMR-based metabolomics. Ecotoxicology 20, 177-186.

Lunt, S.Y., Vander Heiden, M.G., 2011. Aerobic glycolysis: meeting the metabolic requirements of cell proliferation. Annu. Rev. Cell Dev. Biol. 27, 441-464.

Mindnich, R., Möller, G., Adamski, J., 2004. The role of 17 beta-hydroxysteroid dehydrogenases. Mol. Cell. Endocrinol. 218, 7-20.

Montgomery, C., Pei, Z., Watkins, P.A., Miziorko, H.M., 2012. Identification and characterization of an extramitochondrial human 3-hydroxy-3-methylglutarylCoA lyase. J. Biol. Chem. 287, 33227-33236.

Nakagawa, M., Okouchi, H., Adachi, J., Hattori, K., Yamashita, Y., 2007. Effectiveness of stock enhancement of hatchery released black rockfish Sebastes schlegeli in Yamada Bay-evaluation by a fish market survey. Aquaculture 263, 295-302.

Nicholson, J.K., Lindon, J.C., 2008. Metabonomics. Nature 455, 1054-1056.

Palaniappan, P.L.R.M., Vijayasundaram, V., 2009. The effect of arsenic exposure and the efficacy of DMSA on the proteins and lipids of the gill tissues of Labeo rohita. Food Chem. Toxicol. 47, 1752-1759.

Ramsey, K.A., Bosco, A., Mckenna, K.L., Carter, K.W., Elliot, J.G., Berry, L.J., Sly, P.D. Larcombe, A.N., Zosky, G.R., 2013. In utero exposure to arsenic alters lung development and genes related to immune and mucociliary function in mice. Environ. Health Perspect. 121, 244-250.

Rashed, M.N., 2001. Monitoring of environmental heavy metals in fish from nasser lake. Environ. Int. 27, 27-33.

Reichl, F., Szinicz, L., Kreppel, H., Forth, W., 1988. Effect of arsenic on carbohydrate metabolism after single or repeated injection in Guinea pigs. Arch. Toxicol. 62, $473-475$

Rezin, G.T., Cardoso, M.R., Gonc, C.L., Scaini, G., Fraga, D.B., Streck, E.L., Riegel, R.E. Comim, C.M., 2008. Inhibition of mitochondrial respiratory chain in brain of rats subjected to an experimental model of depression. Neurochem. Int. 53, 395-400.

Ruszczyk, A., Joerink, M., Guldenaar, C., Hermsen, T., Savelkoul, H.F., Wiegertjes, G.F., 2008. cDNA expression library screening and identification of two novel antigens: ubiquitin and receptor for activated C kinase (RACK) homologue, of the fish parasite Trypanosoma carassii. Fish Shellfish Immunol. 25, 84-90.

Salazar-Coria, L., Rocha-Gómez, M.A., Matadamas-Martínez, F., Yépez-Mulia, L. Vega-López, M., 2019. Proteomic analysis of oxidized proteins in the brain and liver of the Nile tilapia (Oreochromis niloticus) exposed to a wateraccommodated fraction of Maya crude oil. Ecotoxicol. Environ. Saf. 171, 609-620.

Sears, D.D., Hsiao, G., Hsiao, A., Yu, J.G., Courtney, C.H., Ofrecio, J.M., Chapman, J., Subramaniam, S., 2009. Mechanisms of human insulin resistance and thiazolidinedione-mediated insulin sensitization. Proc. Natl. Acad. Sci. U.S.A. $106,18745-18750$.

Shao, W., Chen, J., Fan, S., Lei, Y., Xu, H., Zhou, J., Cheng, P., Yang, Y., Rao, C., Wu, B., Liu, H., Xie, P., 2015. Combined metabolomics and proteomics analysis of major depression in an animal model: perturbed energy metabolism in the chronic mild stressed rat cerebellum. OMICS 19, 383-392.

Smith, P.K., Krohn, R.I., Hermanson, G.T., Mallia, K., Gartner, F.H., Provenzano, M.D. 1985. Measurement of protein using bicinchoninic acid. Anal. Biochem. 150 76-85.

Song, Y., Cai, T., Yin, Z., Zhang, X., Zhang, W., Oian, Y., Oiu, J., 2018. Stereoselective effects of ibuprofen in adult zebrafish (Danio rerio) using UPLC-TOF/MS-based metabolomics. Environ. Pollut. 241, 730-739.

Szymkowicz, D.B. Sims, K.C. Schwendinger, K.L, Tatnall, C.M. Powell, R.R. Bruce, T.F., Bridges, W.C., Bain, L.J., 2019. Exposure to arsenic during embryogenesis impairs olfactory sensory neuron differentiation and function into adulthood. Toxicology 420, 73-84.

Tian, O Wang J. 2002. Role of serine/threonine protein phosphatase in Alzheimer's disease. Neurosignals 11, 262-269.

Tišler, T., Zagorc-Končan, J., 2002. Acute and chronic toxicity of arsenic to some aquatic organisms. Bull. Environ. Contam. Toxicol. 69, 421-429.

Turrens, J.F., Boveris, A., 1980. Generation of superoxide anion by the NADH dehydrogenase of bovine heart mitochondria. Biochem. J. 191, 421-427.

Viant, M.R., Rosenblum, E.S., Tjeerdema, R.S., 2003. NMR-based metabolomics: a powerful approach for characterizing the effects of environmental stressors on organism health. Environ. Sci. Technol. 37, 4982-4989.

Waarde, A.V., 1983. Aerobic and anaerobic ammonia production by fish. Comp. Biochem. Physiol. B 74, 675-684.

Williams, T.D., Turan, N., Diab, A.M., Wu, H., Mackenzie, C., Bartie, K.L., Hrydziuszko, O., Lyons, B.P., Stentiford, G.D., Herbert, J.M., Abraham, J.K. Katsiadaki, I., Leaver, M.J., Taggart, J.B., George, S.G., Viant, M.R., Chipman, K.J. Falciani, F., 2011. Towards a system level understanding of non-model organisms sampled from the environment: a network biology approach. PLoS Comput. Biol. 7, e1002126. 
Wu, H., Liu, X., Zhang, X., Ji, C., Zhao, J., Yu, J., 2013. Proteomic and metabolomic responses of clam Ruditapes philippinarum to arsenic exposure under different salinities. Aquat. Toxicol. 136-137, 91-100.

Wu, H., Southam, A.D., Hines, A., Viant, M.R., 2008. High-throughput tissue extraction protocol for NMR- and MS-based metabolomics. Anal. Biochem. 372, 204-212.

Xu, H., Lam, S.H., Shen, Y., Gong, Z., 2013. Genome-wide identification of molecular pathways and biomarkers in response to arsenic exposure in zebrafish liver PLoS One 8, e68737.

Xu, L., Ji, C., Wu, H., Tan, Q., Wang, W.-X., 2016. A comparative proteomic study on the effects of metal pollution in oysters Crassostrea hongkongensis. Mar. Pollut. Bull. 112, 436-442.
Yu, D., Ji, C., Zhao, J., Wu, H., 2016. Proteomic and metabolomic analysis on the toxicological effects of as (III) and as (V) in juvenile mussel Mytilus galloprovincialis. Chemosphere 150, 194-201.

Zalkin, H., 1993. Adv. Enzymol. Relat. Area Mol. Biol. 66, 203-309.

Zhang, W., Huang, L., Wang, W.-X., 2012. Biotransformation and detoxification of inorganic arsenic in a marine juvenile fish Terapon jarbua after waterborne and dietborne exposure. J. Hazard Mater. 221-222, 162-169.

Zhang, X., 2001. Investigation of pollution of $\mathrm{Pb}, \mathrm{Cd}, \mathrm{Hg}$, as in sea water and deposit of Bohai Sea area. Heilongjiang Environ. J. 25, 87-90 (in Chinese).

Zhuang, W., Gao, X., 2015. Distributions, sources and ecological risk assessment of arsenic and mercury in the surface sediments of the southwestern coastal Laizhou Bay, Bohai Sea. Mar. Pollut. Bull. 99, 320-327. 